changes (on group and individual level), and percentage observed, positive and negative agreement. Responsiveness was calculated with area under the curve (AUC) obtained from receiver operation characteristic (ROC).

Results A sample of 52 participants on test-retest reliability and agreement and a sample of 223 on responsiveness were included in the study. Of the iPCQ-VR, ICCs ranged from 0.52 to 0.90 , kappa ranged from 0.42 to 0.96 , and AUC ranged from $0.55-0.86$. The ICC of total healthcare utilisation of the TiCP-VR was 0.81 and kappa values of the single healthcare utilisation items ranged from 0.11 to 1 .

Discussion The iPCQ-VR showed good clinimetric properties on working status, number of hours working per week and long term sick leave, and low measurement properties on short term sick leave and presenteeism. The TiCP-VR showed adequate reliability on all healthcare utilisation items together and medication use, but showed low clinimetric properties on the single healthcare utilisation items.

\section{PROGNOSTIC FACTORS FOR WORK PARTICIPATION IN PATIENTS WITH SCIATICA: A SYSTEMATIC REVIEW}

\begin{abstract}
${ }^{1}$ Teddy Oosterhuis, ${ }^{1}$ Veerle R Smaardijk, ${ }^{1}$ PPaul FM Kuijer, ${ }^{2}$ Miranda W Langendam, ${ }^{1}$ Monique HW Frings-Dresen, 'Jan L Hoving*. 'A Academic Medical Centre, Department: Coronel Institute of Occupational Health, Amsterdam Public Health research institute, Amsterdam, The Netherlands; ${ }^{2}$ Academic Medical Centre, University of Amsterdam, Department of Clinical Epidemiology, Biostatistics and Bioinformatics, Amsterdam Public Health research institute, Amsterdam, The Netherlands
\end{abstract}

\subsection{6/oemed-2018-ICOHabstracts.782}

Introduction Sciatica is usually self-limiting with pain and disability decreasing over time, but not all patients fully recover. Prognostic evidence could assist clinicians to better define high risk groups and inform both clinicians and patients with regard to counselling and treatment choices to promote return to work. The objective of this study was to review and summarise prognostic factors of work participation in patients with sciatica.

Methods We searched MEDLINE, CINAHL, EMBASE and PsycINFO till May 2016. Cohort studies, using a measure of work participation as outcome, were included. We used the QUIPS tool for risk of bias assessment and GRADE to rate the quality of the evidence.

Results Based on five studies describing four cohorts $(n=983$ patients) that assessed 19 potential prognostic factors, favourable factors for return to work at long term-term follow up (up to 10 years) included: younger age, better general health, less low back pain or sciatica bothersomeness, better physical function, positive SLR-test, a physician expecting surgery to be beneficial, better pain coping, less depression and mental stress, low physical work load. Study results could not be pooled. Using GRADE, the quality of the evidence ranged from moderate to very low.

Discussion Five studies describing four cohorts identified a wide range of factors: general health, pain and disability, psychological factors and work related factors. Although the number of studies was low and the quality of evidence ranged from moderate to very low, prognostic (modifiable) factors may be used to assist clinicians and occupational healthcare professionals in guiding high risk patients and consider referral for additional care or vocational rehabilitation, or in managing patients' expectations regarding return to work.

\section{4 \\ VALIDATION OF A CONCEPTUAL MODEL FOR SHOULDER PAIN RISK FACTORS IN THREE INDEPENDENT FRENCH WORKING POPULATIONS}

1J Bodin* ${ }^{2,3} \mathrm{R}$ Garlantézec, ${ }^{2} \mathrm{~N}$ Costet, ${ }^{4,5,6} \mathrm{~A}$ Descatha, ${ }^{2,3} \mathrm{JF}$ Viel, ${ }^{1} \mathrm{Y}$ Roquelaure. ${ }^{1}$ INSERM, U1085, IRSET, ESTER Team, University of Angers, Angers, France; ${ }^{2}$ INSERM, U1085, IRSET, 3ERD Team, University Rennes I, Rennes, France; ${ }^{3} \mathrm{CHU}$ Rennes, Rennes, France; ${ }^{4} \mathrm{AP}$-HP UVSQ, Occupational Health Unit, Poincaré University Hospital, Garches, France; ${ }^{5}$ Versailles St-Quentin Univ - Paris Saclay Univ, UMS 011, UMR-S 1168, France; ' INSERM, U1168 UMS 011, Villejuif, France

\subsection{6/oemed-2018-ICOHabstracts.783}

Introduction The aims were to explore the direct and indirect relationships between workplace risk factors, perceived stress and shoulder pain in a sample of male workers from various companies of the industrial sector and to validate the results in workers from two large companies located in France.

Methods Three working populations were analysed: a surveillance network based on a longitudinal design (Cosali) and two samples from companies based on a cross-sectional design. All workers completed a self-administered questionnaire about musculoskeletal symptoms, individual factors and exposure to work constraints. A conceptual model was defined drawing from the literature and the expertise of the authors. Structural equation modelling was used to test the direct and indirect relationships among the variables.

Result Results obtained in the two companies were in majority consistent with those observed in Cosali. In the three samples, industrial constraints influenced physical factors and psychosocial factors whereas market constraints influenced only psychosocial factors. Psychosocial factors and physical factors were correlated and physical factors increased shoulder pain. Shoulder pain was influenced directly by perceived stress only in one sample.

Discussion The results provide a better comprehension of the complexity of the distal and proximal determinants of shoulder pain and highlight that workplace interventions should act on multiple dimensions (i.e. organisational, psychosocial and physical factors) to be more effective.

\section{EFFECTS OF PARTICIPATORY ERGONOMIC INTERVENTION PROGRAM (PEIP) ON MUSCULOSKELETAL AND HEALTH OUTCOMES AMONG HOSPITAL ORDERLIES}

${ }^{1}$ Withaya Chanchai, ${ }^{2}$ Wattasit Siriwong, ${ }^{3}$ Wanpen Songkham, ${ }^{4}$ Pranom Ketsomporn, ${ }^{4}$ Punnarat Sappakitchanchai. ' College of Alied Health Sciences, Sunandha Rajabhat University, Bangkok 10300, Thailand; ${ }^{2}$ College of Public Health Sciences, Chulalongkorn University, Bangkok 10330, Thailand; ${ }^{3}$ Faculty of Nursing, Chiang Mai University, Chiang Mai 50200, Thailand; ${ }^{4}$ Department of Patient transfer service, Faculty of Medicine Siriraj Hospital, Mahidol University, Bangkok 10700, Thailand

\subsection{6/oemed-2018-ICOHabstracts.784}

Introduction The participatory ergonomic (PE) approach has been widely used to improve the health outcomes. The purpose of this study was to assess the effects of the participatory ergonomic intervention program (PEIP) can reduce musculoskeletal and health outcomes among hospital orderlies.

Method The randomised controlled trial (RCT) was conducted at tertiary care hospitals during July to December 2014. There were 100 orderlies participated in this study. Data collection was carried out by self-reported questionnaire and Quick exposure check (QEC) technique. 
Results The musculoskeletal symptom and work ability among the intervention group at post intervention were illustrated the marginal changes trend. This study found that sick leave among orderlies in the intervention group did not decrease. An explanation for the lack of decreased sick leave is that physical risk factors were addressed during the intervention period. During short follow up ( 2 months), the positive outcome of the PEIP program within the intervention group had proven by the number of health outcomes achievements carried out by orderlies. QEC scores were found illustrated the marginal changes trend for the lower back, hips/thighs and then upper back among the intervention group at post intervention, whereas the scores for the shoulder/arm, wrist/hand and neck were not found the marginal changes trend for static use and moderate for moving.

Discussion This study suggests that the substantial improvements in work environments and health outcomes among healthcare worker were seen following participatory ergonomic (PE) approach.

\section{A MULTIDISCIPLINARY CASE STUDY TO OPTIMISE ERGONOMIC WORK CONDITIONS IN A NEW DISTRIBUTION CENTRE AT THE WORLD'S LEADING SPORTS BRAND}

${ }^{1} \mathrm{~N}$ Maes, ${ }^{2} \mathrm{G}$ Pollentier ${ }^{*},{ }^{2} \mathrm{~S}$ Acke, ${ }^{2} \mathrm{E}$ Verbeek, ${ }^{2} \mathrm{D}$ Delaruelle, ${ }^{2} \mathrm{~K}$ Eerdekens, ${ }^{2} \mathrm{M}$ N Schmickler. 'Department of Health, Safety and Environmental Risks, Nike, Belgium; ${ }^{2}$ Mensura Occupational Health Services, Belgium

10.1136/oemed-2018-ICOHabstracts.785

Introduction Discharging a container/trailer is physically very stressful. This study describes a multidisciplinary and solutions oriented approach in a newly constructed Distribution Centre (DC).

Methods The setting is the European DC of a sports brand with 2,205 Belgian operators. The project is focused on innovative solutions for the area where the receiving of footwear is done. Repetitive movements and lifting resulted in musculoskeletal complaints that were reported to the occupational physician via the yearly Nordic Musculoskeletal questionnaire surveillance.

The ergonomist implemented the following four-step multidisciplinary approach:

- Risk stratification (employee, equipment, environment, product and organisation)

- External workload evaluation (task analysis/observation, Key Indicator Method (KIM), ISO 11228 standard, noise and illumination)

- Internal physical workload examination (heart rate)

- Participatory subjective work perception index

Results The important results of the external workload evaluation are described below:

a. Observation. The ergonomic 'manrider' tool needs additional ergonomic improvements.

b. KIM. Women doing the receiving for 3.5 to 7.25 hours scored 55: 'Heavy workload: physical overload is likely. Workplace re-design is necessary.' Men scored 45: 'Strongly increased workload; physical overload is possible. Workplace re-design is recommended.'

c. ISO 11228. The recommended weight limit (RWL) at the end of the shift for men/women with a height of $148 \mathrm{~cm}$ was 2.03; for women with a height of $180 \mathrm{~cm}$, the RWL was 1.99; and for men with a height of $195 \mathrm{~cm}$, the RWL was 1.98. The Lift-Index for these groups was 3.46, 3.53 and 3.55 , respectively, resulting in a higher risk for lower back pain.

d. Illumination at the end of the trailer was 192 and 308 lux. At the end of the container, 32.1, 11.7, 11, 11.3 and 43.3 lux was measured. The NBN-EN 12464-1 standard for illumination (minimum 200 lux) was insufficiently achieved.

Discussion A multidisciplinary approach is recommended to optimise ergonomic work conditions.

\section{RHIZARTHROSIS IN BANKNOTE PROCESSING WORKERS: A RETROSPECTIVE COHORT STUDY}

${ }^{1} \mathrm{G}$ Verrijdt, ${ }^{2} \mathrm{~A}$ De Landtsheer*, ${ }^{1} \mathrm{~A}-\mathrm{M}$ Mellen, ${ }^{3} \mathrm{~L}$ Godderis. ${ }^{1}$ FEDRIS Federal Agency for Occupational Risks, Brussels, Belgium; ${ }^{2}$ National Bank of Belgium Occupational Health Department, Brussels, Belgium; ${ }^{3} \mathrm{KU}$ Leuven University Environment and Health department, Leuven, Belgium

\subsection{6/oemed-2018-ICOHabstracts.786}

Introduction Rhizarthrosis is a common condition affecting $10 \%$ to $30 \%$ of the population over the age of 60 . Whether or not it is an occupational disease has been the subject of debate as epidemiological studies on the correlation between physical stress and the presence of rhizarthrosis have shown conflicting results. A cluster of cases among banknote processing workers was reported by the OHP to the Federal Agency for Occupational Risks for evaluation

Methods We have set up a retrospective cohort study covering195 employees currently or previously involved in the manual or automated processing of banknotes. Each participant's job history was carefully reconstructed and the number of months holding certain job titles determined. Each participant was clinically and radiologically examined for the presence of rhizarthrosis in both hands, scored by a combination of clinical and radiological criteria and related to exposure.

Results The prevalence of rhizarthrosis was $27 \%$ in female participants (mean age: $52.3 \mathrm{y} \pm 4.4 \mathrm{y}$ ) and $17 \%$ in male participants (mean age: $53.2 \pm 5.8 \mathrm{y}$ ). The odds ratio for rhizarthrosis after 10 years' full-time overall exposure was significantly higher (OR10y: 1.53 (1.03-2.28)). Surprisingly, one particular job, 'manual counting', described by participants as highly straining and severely taxing on the thumbs, has not shown any significantly higher prevalence of rhizarthrosis.

Conclusion Our study has confirmed the correlation between the presence of rhizarthrosis and age, gender and manual repetitive work. We found a significantly higher risk for banknote processing in general but not for one particular job ('manual counting'), although considered by participants as a strenuous effort for the thumbs.

Discussion This is the first study on the risk of developing rhizarthrosis in banknote processing workers. The result indicates they are at greater risk and calls for adequate occupational health monitoring to prevent irreversible damage to the CMC-1 joint. 